\title{
Fulminating chromobacterial septicaemia presenting as respiratory distress syndrome
}

\author{
TS LEE, BALLARD D WRIGHT \\ From the University of Kentucky Medical Center, Lexington, Kentucky, USA
}

Respiratory distress syndrome occurs in a variety of clinical situations of which sepsis is one important precipitating factor. We have observed and successfully treated with high PEEP (positive end-expiratory pressure) a rare case of chromobacterial septicaemia complicated by an acute respiratory distress syndrome. We describe here the first reported case of a patient in this country surviving this illness with pulmonary involvement.

\section{Case report}

A 3-year-old white male had been healthy until six days before admission when he developed lethargy, high fever, and bug-bite-like nodular skin lesions on his left hip. This occurred while he and his family were on holiday in Florida. He was admitted to a local hospital and found to have leucocytosis $\left(24.8 \times 10^{9} / \mathrm{l}\right)$ with a left shift. The discharge from the skin eruptions was cultured and revealed gram-negative rods which were identified as chromobacteria. He was given gentamicin $(7 \mathrm{mg} / \mathrm{kg} /$ day $)$ and ampicillin $(100 \mathrm{mg} / \mathrm{kg} /$ day $)$, which was soon replaced by carbenicillin $(600 \mathrm{mg} / \mathrm{kg} /$ day $)$ when the chromobacteria proved to be ampicillin-resistant. The patient remained febrile, pustules and ulcerative lesions appeared on his extremities, his right index finger became swollen and gangrenous, and he developed grey, watery diarrhoea.

The patient was then transferred to the University of Kentucky Medical Center at his parent's request. On arrival, his body temperature was $41^{\circ} \mathrm{C}$, pulse $140 /$ minute, respiration $25 /$ minute, and blood pressure $120 / 70 \mathrm{~mm} \mathrm{Hg}$. His chest was clear and chest radiographs were normal. A grade II/VI systolic ejection murmer was audible at the apex and left sternal border. White blood count was $22 \cdot 1 \times 10^{9} / 1$ and haematocrit $40 \%$. Prothrombin time and partial thromboplastin time were within normal limits. Liver function tests showed an increased serum glutamic oxaloacetic transaminase. Tenderness and pain in the knee joints was noted.

On the second day after transfer, gentamicin was increased to $13 \mathrm{mg} / \mathrm{kg} /$ day and Bactrim (cotrimoxazole) $100 \mathrm{mg} / \mathrm{kg} /$ day was added. When the patient developed rapidly-worsening tachypnoea, chest radiographs showed the sudden appearance of a bilateral diffuse nodularpatchy infiltration that suggested a possible septic embolisation to the lungs (fig 1). While breathing room air, the patient had an arterial oxygen tension of $22 \mathrm{~mm}$

Address for reprint requests: Dr TS Lee, University of Kentucky Medical Center, 800 Rose Street, Lexington, Kentucky 40536, USA.
$\mathrm{Hg}(2.93 \mathrm{kPa})$, an arterial carbon dioxide tension of $42 \mathrm{mmHg}(5 \cdot 60 \mathrm{kPa})$, and an arterial $\mathrm{pH}$ of $7 \cdot 3$. Chest radiographs taken shortly thereafter had changed to near total bilateral homogeneous infiltration (fig 2). The patient quickly deteriorated and suffered cardiopulmonary arrest. He was resuscitated three times and placed on mechanical ventilation.

At this time, with $\mathrm{FiO}_{2}$ at $1 \cdot 0$, tidal volume at $250 \mathrm{ml}$, PEEP as high as $15 \mathrm{~cm} \mathrm{H}_{2} \mathrm{O}$, and respiratory rate of $26 /$ minute, arterial blood gases remained constant at pH 7·2-7.3, $\mathrm{PCO}_{2} 54-60 \mathrm{mmHg}(7 \cdot 20-8 \cdot 0 \mathrm{kPa})$, and $\mathrm{Po}_{2}$ 25-35 mmHg (3-33-4.67 kPa). Calculated static lung compliance was below $10 \mathrm{ml} / \mathrm{cm} \mathrm{H}_{2} \mathrm{O}$. A Swan-Ganz catheter was inserted. The pulmonary artery pressure was $40 / 25 \mathrm{mmHg}$ with a mean of $30 \mathrm{mmHg}$, and the pulmonary capillary wedge pressure was $13 \mathrm{mmHg}$. PEEP was then increased to $20 \mathrm{~cm} \mathrm{H}_{2} \mathrm{O}$; arterial oxygenation improved to $76 \mathrm{mrnHg}(10 \cdot 1 \mathrm{kPa})$, and static compliance increased to $21 \mathrm{ml} / \mathrm{cm} \mathrm{H}_{2} \mathrm{O}$. The patient's pupils began to react. Despite barotraumatic pneumomediastinum, pulmonary interstitial emphysema, and subcutaneous emphysema, the patient's respiratory function was satisfactory with an arterial oxygen saturation of 87$98 \%$, a $\mathrm{PaCO}_{2}$ of $38-46 \mathrm{mmHg}(5 \cdot 07-6 \cdot 13 \mathrm{kPa})$, and a stable $\mathrm{pH}$. $\mathrm{FiO}_{2}$ and PEEP were gradually decreased, and the patient was weaned with intermittent mandatory ventilation (IMV) on the eleventh day of artificial ventilation (fig 3). During this period, he had three positive blood cultures for chromobacterium violaceum

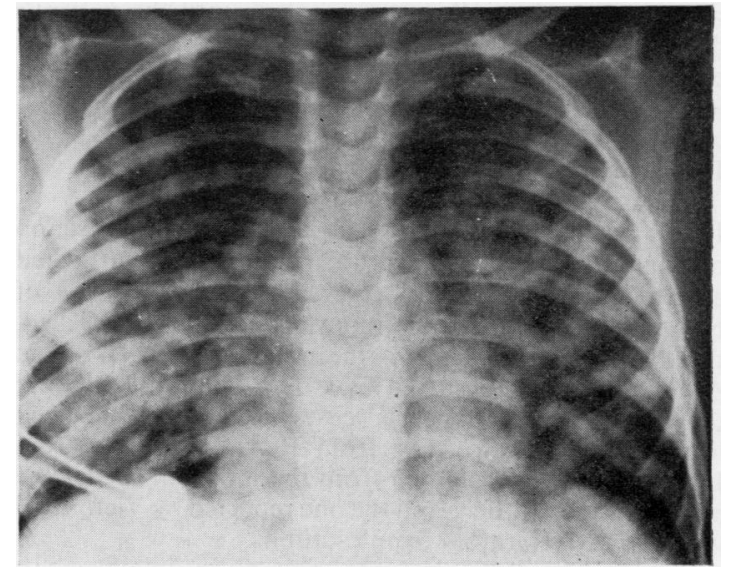

Fig 1 Bilateral diffuse nodular-patchy infiltration suggesting a possible septic embolisation to the lungs. 


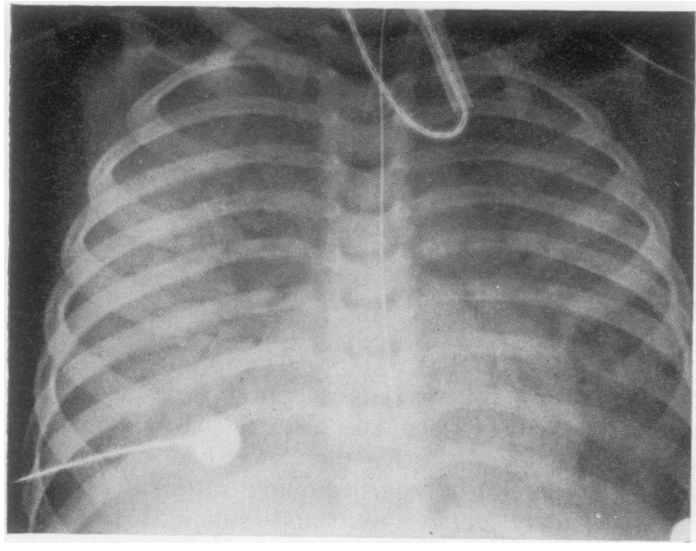

Fig 2 Near total homogeneous infiltration with air bronchogram.

and developed positive chromobacterial osteomyelitis of the left knee (fig 4), which was drained surgically. The child also suffered right ankle cellulitis and spontaneous amputation of the right index finger. The skin lesions which had begun as pustules progressed to dry gangrene.

Susceptibility tests on the chromobacterium proved it to be resistant to ampicillin, carbenicillin and cephalothin and sensitive to chloramphenicol, polymixin B, gentamicin, kanamycin, tobramycin, tetracycline, and Bactrim. The patient continued to receive gentamicin and Bactrim, but carbenicillin was discontinued when the organism was found to be resistant to it. His general condition improved remarkably, and he became afebrile after drainage of the left knee lesion. Gentamicin was stopped after 26 days of therapy because of increasing evidence of toxicity, namely hearing impairment and decreased creatinine clearance. At that time, serial cultures of blood and wounds had been negative for three weeks and one week, respectively. Bactrim remained the only antibiotic prescribed until the patient's discharge from the hospital. The chest radiograph was clear on discharge with the exception of a small cystic lesion in the left lower lobe.

\section{Discussion}

It was not until Black first reported in 1938 its infection of a human being that chromobacterium was considered a pathogenic organism. ${ }^{1}$ At present, only 19 cases of human infection have been reported,,$^{1-8}$ of which 14 died, three survived, and in two the outcome is not known. Almost all cases occurred in tropical areas. Including the present case, only six cases have been reported in the United States, five from Florida, and one from Louisiana. ${ }^{1-3}$ \& 8 All died from the infection except the patient presented here and the one reported by Victorica, ${ }^{8}$ who had no respiratory manifestations.

Skin lesions, liver abscesses, pulmonary involvement, and sepsis appear to be characteristic of most patients with chromobacterial infections. ${ }^{1-8}$ Interestingly, even though respiratory failure has not been claimed as the primary cause of fatality, a varying degree of pulmonary involvement has been mentioned in several cases. ${ }^{3-i} \bar{O}$ Nunnally $^{5}$ and Ognibene ${ }^{7}$ described acute respiratory crises of dyspnoea and cyanosis associated with extensive $\frac{\bar{\sigma}}{\bar{p}}$ infiltrative processes. The necropsy report of another $\vec{\nabla}$ patient showed an excessively heavy lung weight suggest- 0

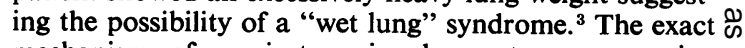
mechanism of respiratory involvement accompanying $\vec{\circ}$ sepsis is still uncertain. Gross disturbance of clotting systems with intravascular coagulation and direct
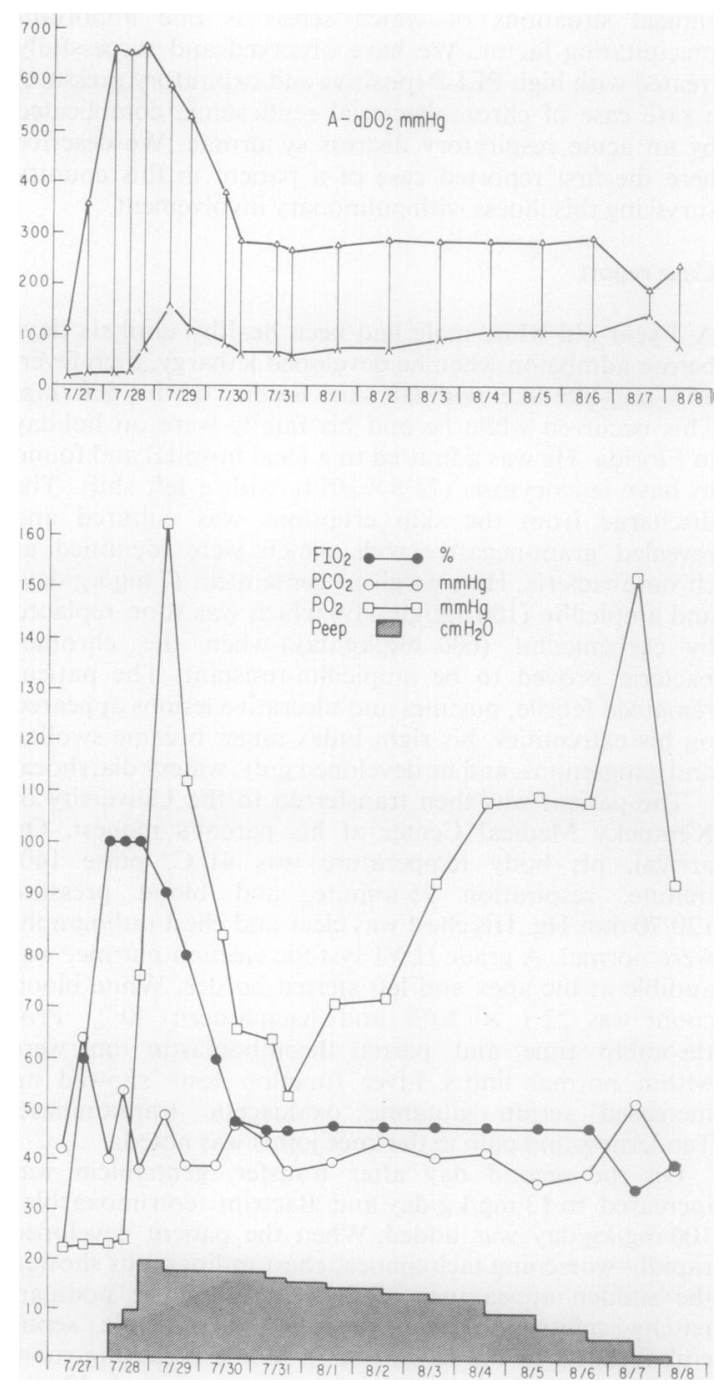

Fig 3 Change of arterial blood gases during the course of respiratory insufficiency. Note severe hypoxaemia and wide $A-a D O_{2}$ before institution of high PEEP. Conversion: $1 \mathrm{mmHg}=0.133 \mathrm{kPa}$. 


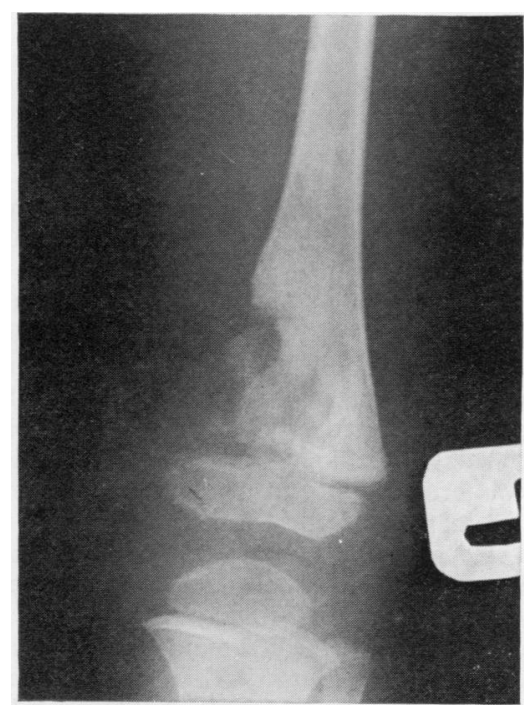

Fig 4 Osteomyelitis of the left knee with extensive moth-eaten lesion in the distal femur.

endothelial damage with increased capillary permeability have been described as two important factors. ${ }^{2-11}$

In the case presented here, sepsis was followed by the development of intractable hypoxaemia with a wide $\mathrm{A}-\mathrm{aDO}_{2}$ shunt, remarkable decrease in lung compliance, a picture of non-cardiogenic pulmonary oedema on the chest radiographs, and response to a high PEEP level, all of which clinically suggested a respiratory distress syndrome. ${ }^{12}$

Based on this experience, although not clearly defined, we suspect that acute respiratory distress syndrome may have been one of the significant causes contributing to the death of the previously reported cases.

We would like to thank Marilyn W Schrader, CRTT, BA, and Miss June Land for editorial and secretarial assistance.

\section{References}

1 Black ME, Shahan J. Bacillus violaceus infection in a human being. JAMA 1938;110:1270-1.

2 Soule MH. A study of two strains of $b$ violaceus isolated from human beings. Am J Pathol 1939;15:592.

3 Schattenberg HJ, Harris WH. A definite and unique occurrence of rapidly fatal infection casued by bacillus violaceus manilae. JAMA 1941 ;117:2069-70.

${ }_{4}$ Sneath PHA. Singh RB, Whelan JPG, Edwards D. Fatal infection by chromobacterium violaceum. Lancet 1953; 2:276-7.

5 Nunnally RM, Dunlop WH. Fatal septicemia due to chromobacterium janthinum. J Louisiana State $M$ Soc $1968 ; 120: 278-80$.

6 Dauphinais RM, Robben CG. Fatal infection due to chromobacterium violaceum. Am J Clin Pathol 1968; 50:592-7.

7 Ognibene AJ, Thomas E. Fatal infection due to chromobacterium violaceum in Vietnam. Am J Clin Pathol 1970; $54: 607-10$

8 Victorica B, Baer H, Ayoub EM. Successful treatment of systemic chromobacterium violaceum infection. JAMA $1974 ; 230: 578-80$.

9 Groves AC et al. Fibrin thrombi in the pulmonary microcirculation of dogs with gram-negative bacteremia. Surg Gynecol Obstet 1972;134:433.

10 Pennington DG, Hyman A, Jacques WE. Pulmonary vascular response to endotoxin in intact dogs. Surgery 1973;73:246.

11 Brigham KL, Woolverton WC, Staub NC. Reversible increase in pulmonary vascular permeability after pseudomonas aeruginosa bacteremia in unanesthetized sheep. Chest 1974;65:51.

12 Petty TL, Ashbaugh DG. The adult respiratory distress syndrome. Chest $1971 ; 60: 233$. 